Scientific paper

\title{
Development of Structure-Property Relationships for Concrete
}

\author{
Tewodros T. Ghebrab ${ }^{1}$ and Parviz Soroushian ${ }^{2}$
}

Received 17 April 2010, accepted 21 December 2010

\begin{abstract}
:
Theoretical models are developed for the prediction of the mechanical properties of mature concrete based on the morphology and interactions of its constituents. The models account for the morphology and interactions of cement hydration products, the capillary pores and microcracks. Concrete is modeled as a three-phase material composed of cement mortar, coarse aggregates and ITZ. The modulus of elasticity of concrete is determined using the Hashin's bound model for three-phase composites. Modeling of fracture toughness indicates that the frictional pull-out of coarse aggregates makes major contributions to the fracture energy of concrete. A tensile strength model is developed for concrete based on linear elastic fracture mechanics theories. The predicted theoretical models are in reasonable agreement with empirical models reflecting the experimental performance of concrete.
\end{abstract}

\section{Introduction}

Theoretical models based on the morphology and interactions of cement hydration products are used in the prediction of the mechanical properties of concrete. The models account for intermolecular levels of nano-scale calcium silicate hydrate $(\mathrm{C}-\mathrm{S}-\mathrm{H})$ particles, capillary porosity and microcracking within hydrated cement paste. The effect of the interfacial transition zone on the mechanical properties of concrete was also considered in developing the theoretical models. The objective of this research was to develop models for the mechanical properties of concrete that are based on structureproperty relationships and account for the molecular interactions of the phases present in the concrete structure. These models may help in predicting the mechanical properties of concrete with a modification of the structure of its phases.

Concrete is a composite material with properties that are affected by the arrangement, characteristics and proportions of its constituent materials. The phases present in concrete are the cement mortar, coarse aggregate, and the interfacial transition zone (ITZ), which surrounds coarse aggregates with a thickness of 30-50 $\mu \mathrm{m}$ (Dhir 2005). When compared with the bulk hydrated cement paste (hcp) in mortar, ITZ has much higher porosity and calcium hydroxide $(\mathrm{CH})$ volume fraction, and lower contents of calcium silicate hydrate $(\mathrm{C}-\mathrm{S}-\mathrm{H})$. This is attributed, to some extent, to the higher volume fraction and the lower packing of C-S-H near the surface of coarse aggregates (Dhir 2005; Bisschop and van Mier 1999). The ITZ is generally the weakest phase of concrete (Scrivener 1989), and its presence adds to the

\footnotetext{
${ }^{1}$ Assistant Professor, Department of Construction Engineering, Texas Tech University, Lubbock, TX, USA E-mail: tewodros.ghebrab@ttu.edu

${ }^{2}$ Professor, Department Civil and Environmental Engineering, Michigan State University, MI, USA.
}

complexity of concrete.

Theoretical models are developed in the research reported herein for expressing the mechanical properties of concrete in terms of its composite structure, with due consideration given to the distinguishing features of the ITZ.

\section{Modulus of elasticity of concrete}

The elastic modulus of concrete can be expressed in terms of the elastic, bulk and shear moduli of its constituent phases. For cement mortar, the following modulus of elasticity model (Eq. 1) developed by the authors (the detailed procedure for the development of the model is described in a paper submitted for publication to IJCSM) was used.

$$
E_{m} \approx \frac{5.78 E_{h}^{2}-28.35 E_{h}}{0.04 E_{h}^{2}+2.43 E_{h}-12.46}
$$

where $\mathrm{Em}=$ modulus of elasticity of cement mortar (in $\mathrm{GPa}$ ) and $\mathrm{Eh}=$ modulus of elasticity of hep (in GPa).

The porosity of the ITZ was considered to be about twice that of hcp (Garboczi et al. 2000). This rise in porosity was accounted for in modeling the elastic modulus of the ITZ $\left(E_{\text {ic }}\right)$ using that of the hcp $\left(E_{\mathrm{h}}\right)$ model. The modulus of elasticity of coarse aggregates $\left(E_{\mathrm{ca}}\right)$ ranges from $70 \mathrm{GPa}$ to $90 \mathrm{GPa}$, depending upon the type of aggregate (Hsu et al. 1963). A sensitivity analysis was conducted to evaluate the significance of this range in determining the elastic modulus of concrete.

The upper and lower bounds of the elastic modulus of concrete were calculated using equations relating the modulus of elasticity of a composite material to its shear modulus $\left(G_{\mathrm{c}}^{\prime}\right)$ and bulk modulus $\left(K_{\mathrm{c}}^{\prime}\right)($ Eq. 2$)$ (Mindess et al. 2003). The upper and lower bounds of the shear modulus and bulk modulus were calculated using Hashin's modulus of elasticity model for three-phase 
composite materials (Eqs. 3 to 6) (Mindess et al. 2003).

$$
\frac{9 K_{c-}^{\prime} G_{c-}^{\prime}}{3 K_{c-}^{\prime}+G_{c-}^{\prime}} \leq E_{c} \leq \frac{9 K_{c+}^{\prime} G_{c+}^{\prime}}{3 K_{c+}^{\prime}+G_{c+}^{\prime}}
$$

where $K_{c+}^{\prime}$ and $K_{c-}^{\prime}=$ upper and lower bounds of the bulk modulus of concrete, respectively,

$G_{c+}^{\prime}$ and $G_{c-}^{\prime}=$ upper and lower bounds of the shear modulus of concrete, respectively (Mindess et al. 2003).

These parameters were calculated as follows:

Lower bound of the bulk modulus of concrete, $K_{c-}^{\prime}$ (Mindess et al. 2003),

$$
\frac{1}{K_{c-}^{\prime}}=\frac{V_{m}^{\prime}}{K_{m}^{\prime}}+\frac{V_{c a}^{\prime}}{K_{c a}^{\prime}}+\frac{3 V_{c a}^{\prime} t_{r c}}{K_{i c}^{\prime}+1.33 G_{i c}^{\prime}}
$$

Upper bound of the bulk modulus of concrete, $K_{c+}^{\prime}$ (Mindess et al. 2003),

$$
K_{c+}^{\prime}=V_{m}^{\prime} K_{m}^{\prime}+\frac{V_{c a}^{\prime} K_{c a}^{\prime}}{1+\frac{3 K_{c a}^{\prime} t_{r c}}{K_{i c}^{\prime}+1.33 G_{i c}^{\prime}}}
$$

Lower bound of the shear modulus of concrete, $G_{c-}^{\prime}$ (Mindess et al. 2003),

$$
\begin{aligned}
& \frac{1}{G_{c-}^{\prime}}=\frac{V_{m}^{\prime}}{G_{m}^{\prime}}+\frac{V_{c a}^{\prime}}{G_{c a}^{\prime}}+ \\
& +0.4 V_{c a}^{\prime} t_{r c}\left(\frac{2}{K_{i c}^{\prime}+1.33 G_{i c}^{\prime}}+\frac{6}{G_{i c}^{\prime}}\right)
\end{aligned}
$$

Upper bound of the shear modulus of concrete, $G_{c+}^{\prime}$ (Mindess et al. 2003),

$$
G_{c+}^{\prime}=V_{m}^{\prime} G_{m}^{\prime}+\frac{V_{c a}^{\prime} G_{c a}^{\prime}}{1+\frac{2.5 G_{c a}^{\prime} t_{r c}}{K_{i c}^{\prime}+3.33 G_{i c}^{\prime}}}
$$

where $V^{\prime}, G^{\prime}$ and $K^{\prime}$ refer to volume fraction, shear modulus and bulk modulus, respectively, subscripts $\mathrm{m}$, ca and ic refer to mortar, coarse aggregate and ITZ, and trc is the ratio of the thickness of the ITZ in concrete to the radius of an equivalent sphere representing coarse aggregates (Mindess et al. 2003), and was calculated as follows:

$$
t_{r c}=\frac{t_{i c}}{r_{c a}}
$$

where $t_{\text {ic }}=$ thickness (in m) of the ITZ in concrete (a function of the coarse aggregate size) (Mindess et al. 2003); $r_{\mathrm{ca}}=$ radius of an equivalent spherical coarse aggregate (in $\mathrm{m}$ ).

The thickness of the ITZ in concrete $\left(t_{\mathrm{ic}}\right)$ is proportional to the size of the coarse aggregate it envelops (Mindess et al. 2003).

The next step was to determine all the parameters included in the above equations. The bulk modulus and shear modulus of any material are related to its modulus of elasticity through Eqs. 8 and 9, respectively (Mindess et al. 2003).

$$
\begin{aligned}
K^{\prime} & =\frac{E}{3(1-2 v)} \\
G^{\prime} & =\frac{E}{2(1+v)}
\end{aligned}
$$

where $v$ : the poison's ratio.

From the above relationships, the bulk modulus and shear modulus of cement mortar and coarse aggregates were calculated as follows $(v=0.2$ was considered for both cement mortar and coarse aggregates (Mehta and Monteiro 1993; Yang 1996; Gercek 2007)):

The bulk modulus of cement mortar, $K_{m}^{\prime}$ (in GPa),

$$
K_{m}^{\prime}=\frac{E_{m}}{3(1-2 v)}=\frac{E_{m}}{3(1-2(0.2))}=0.56 E_{m}
$$

The bulk modulus of coarse aggregate, $K_{c a}^{\prime}$ (in GPa),

$$
K_{c a}^{\prime}=\frac{E_{c a}}{3(1-2 v)}=\frac{E_{c a}}{3(1-2(0.2))}=0.56 E_{c a}
$$

The shear modulus of cement mortar, $G_{m}^{\prime}$ (in GPa),

$$
G_{m}^{\prime}=\frac{E_{m}}{2(1+v)}=\frac{E_{m}}{2(1+0.2)}=0.42 E_{m}
$$

The shear modulus of coarse aggregate, $G_{c a}^{\prime}$ (in GPa),

$$
G_{c a}^{\prime}=\frac{E_{c a}}{2(1+v)}=\frac{E_{c a}}{2(1+0.2)}=0.42 E_{c a}
$$

Using a similar approach, the bulk modulus and the shear modulus of the ITZ of concrete could be determined as follows:

$$
\begin{aligned}
& K_{i c}^{\prime}=0.56 E_{i c} \\
& G_{i c}^{\prime}=0.42 E_{i c}
\end{aligned}
$$

With the elastic modulus of normal-weight coarse aggregate $\left(E_{\mathrm{ca}}\right)$ typically ranging from 70 to $90 \mathrm{GPa}$, the corresponding values of $K^{\prime}{ }_{\mathrm{ca}}$ and $G_{\mathrm{ca}}$, range from 39.2 to $50.4 \mathrm{GPa}$ and 29.4 to $37.8 \mathrm{GPa}$, respectively. The results of a parametric study will be presented in the next section on the sensitivity of concrete elastic modulus to the variation of the coarse aggregate elastic modulus within the typical range. The modulus of elasticity of the ITZ in concrete $\left(E_{\mathrm{ic}}\right)$ is a function of the modulus of elasticity of cement mortar $\left(E_{\mathrm{m}}\right)$ and the capillary porosity of the transition zone. This relationship is shown in the next section.

The next step was to develop a relationship between the ITZ thickness and aggregate size in concrete. This relationship was approximated to be linear. The size of coarse aggregates considered in this analysis ranges 
from 4 to $25 \mathrm{~mm}$. The maximum thickness of the ITZ is about $50 \mu \mathrm{m}$ (Bisschop and van Mier 1999; Scrivener et al. 2004). This thickness was considered to occur around coarse aggregates of $25 \mathrm{~mm}$ size, which represents a common maximum coarse aggregate size in concrete. No ITZ was assumed to occur for aggregates that are smaller than $0.1 \mathrm{~mm}$ in size. This assumption is based on the fact that no ITZ has been detected so far around $\mathrm{CH}$ crystals of the same size. It was thus assumed that the ITZ thickness, tr, linearly varies from 3.9 to $50 \mu \mathrm{m}$ with aggregate size varying from 4 to $25 \mathrm{~mm}$. A sensitivity analysis of the significance of this range in deciding the elastic modulus of concrete is presented in the next section.

The significance of the three phases (cement mortar, coarse aggregates and ITZ) in determining the mechanical properties of concrete also depends on their respective volume proportions in concrete. Calculations of the volume fractions of cement mortar $\left(V_{m}^{\prime}\right)$, coarse aggregate $\left(V_{c a}^{\prime}\right)$ and ITZ $\left(V_{i c}^{\prime}\right)$ in concrete are discussed below. Porosity of the ITZ in concrete $\left(P_{\mathrm{ic}}\right)$ is about two times that of the hep (Garboczi et al. 2000).

In a normal concrete mix, the total aggregate volume comprises about $75 \%$ of the total volume of concrete. Since the fine-to-coarse aggregate volumetric ratio in concrete is about $2: 3$, fine and coarse aggregates typically comprise about $30 \%$ and $45 \%$, respectively, of the total volume of concrete. Therefore, a typical volume of fraction of cement mortar in concrete (including the ITZ), calculated as the sum of the volume fractions of the hcp $(\sim 0.25)$ and the fine aggregate $(\sim 0.3)$, can be estimated at about 0.55 . The volume of ITZ surrounding a single coarse aggregate in concrete (V1ic) can be calculated based on the relationship between the aggregate size and the thickness of ITZ. The shape of coarse aggregate is typically modeled as spherical, cylindrical or cubic. Evaluation of the geometry of a random sample of concrete coarse aggregate has indicated that a cylindrical shape with aspect (height-to-diameter) ratio of about 1.25 (Fig. 1) would reasonably represent the coarse aggregates used in concrete (Erdogan et al. 2006).

The volume of the ITZ of thickness tic surrounding a single coarse aggregate with a shape shown in Fig. 1 can be calculated as follows:

$$
V_{1 i c}=\pi t_{i c}\left(7 r_{c a}^{2}+6.5 r_{a} t_{i c}+2 t_{i c}^{2}\right)
$$

where $V_{\text {lic }}=$ the volume (in $\mathrm{m}^{3}$ ) of ITZ surrounding a

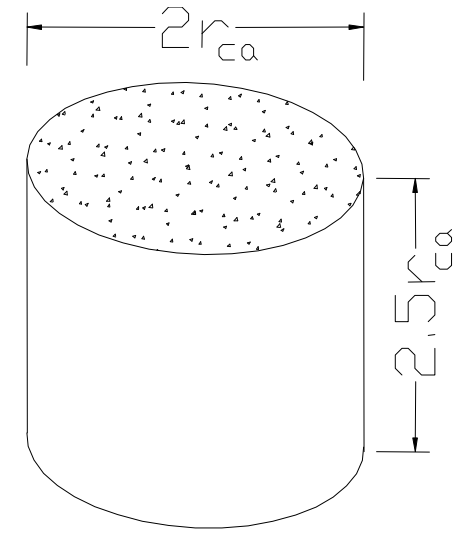

Fig. 1 Coarse aggregate shape model.

single coarse aggregate in concrete.

Assuming a uniform coarse aggregate size, the number of coarse aggregates per unit volume of concrete $\left(N_{\text {ca }}\right)$ can be calculated as follows:

$$
N_{c a}=\frac{V_{c a}}{V_{1 c a}}=\frac{V_{c a}}{2.5 \pi r_{c a}^{3}}
$$

where $V_{\text {lca }}=$ the volume (in $\mathrm{m}^{3}$ ) of a single cylindrical coarse aggregate with radius of rca and height of $2.5 r_{\mathrm{ca}}$.

The total volume of the ITZ $\left(\mathrm{V}_{\mathrm{ic}}\right.$, in $\left.\mathrm{m}^{3}\right)$ can then be calculated as the product of $N_{\mathrm{ca}}$ and $V_{\text {lic }}$ :

$$
V_{i c}=V_{1 i c} N_{c a}
$$

For typical concrete mix proportions, the volume of the ITZ is typically below $1 \%$. Since the thickness of the ITZ is proportional to the size of the coarse aggregates in concrete, the volume fraction of the ITZ (and thus that of mortar) remain constant as the coarse aggregate size changes at constant coarse aggregate volume fraction (Table 1).

\section{Sensitivity analysis of the influence of coarse aggregate elastic modulus on the concrete elastic modulus}

Since the elastic modulus of normal-weight coarse aggregates used in concrete ranges from 70 to $90 \mathrm{MPa}$, a parametric study was conducted to assess the sensitivity of the concrete elastic modulus to that of coarse aggre-

Table 1 Volume fractions of ITZ and cement mortar for different sizes of coarse aggregates at a constant coarse aggregate volume fraction of 0.45 in concrete.

\begin{tabular}{|c|c|c|c|c|c|c|}
\hline$r_{c a}(\mathrm{~m})$ & $t_{i c}(\mathrm{~m})$ & $t_{r c}$ & $V_{1 i c}\left(\mathrm{~m}^{3}\right)$ & $N_{c a}$ & $\bar{V}_{i c}$ & $\bar{V}_{m}$ \\
\hline $2.0 \times 10^{-3}$ & $8.0 \times 10^{-6}$ & $4.0 \times 10^{-3}$ & $7.06 \times 10^{-10}$ & $7.16 \times 10^{-6}$ & 0.005 & 0.545 \\
\hline $7.0 \times 10^{-3}$ & $2.8 \times 10^{-5}$ & $4.0 \times 10^{-3}$ & $3.03 \times 10^{-8}$ & $1.67 \times 10^{-5}$ & 0.005 & 0.545 \\
\hline $1.2 \times 10^{-2}$ & $4.8 \times 10^{-5}$ & $4.0 \times 10^{-3}$ & $1.53 \times 10^{-7}$ & $3.32 \times 10^{-4}$ & 0.005 & 0.545 \\
\hline
\end{tabular}


gate over this range. In this sensitivity analysis, all the parameters related to hcp and mortar were taken constant at typical levels. From Table 1, $V_{m}^{\prime}=0.545$, $V_{i c}^{\prime}=0.005$ and $V_{c a}^{\prime}=0.45$ were considered for determining the elastic modulus of concrete. The elastic modulus of the ITZ in concrete (Eq. 19) was then developed by modifying the elastic modulus of mortar (Eq. 1) with a capillary porosity twice that of a regular mortar.

$$
E_{i c}=3.4\left(1-2 p_{h}\right) \frac{\left(\pi-8 p_{h}\right)^{0.37}}{p_{h}^{0.37}}
$$

where $E_{\text {ic }}$ (in GPa) is the elastic modulus of ITZ in concrete; and $p_{\mathrm{h}}$ is capillary porosity.

The values of $E_{\mathrm{m}}$ and $E_{\text {ic }}$ were calculated using Eqs. 1 and 19 , respectively, for a reasonable range of capillary porosity in concrete (Table 2).

An approximate relationship was then developed between $E_{\mathrm{m}}$ and $E_{\mathrm{ic}}$ by plotting the corresponding values from Table 2, and fitting a curve as shown in Fig. 2. The resulting relationship is shown below.

$$
E_{i c}=0.447 E_{m}-5.01
$$

Three aggregate sizes $(8,16$ and $20 \mathrm{~mm})$ were considered in evaluating the elastic moduli of concrete, and the results indicated that the upper and lower bounds of concrete shear and bulk moduli do not change considerably with aggregate sizes. The reason for this is that the bulk and shear moduli of a material, as shown in their corresponding equations, depend upon the volume fractions and elastic moduli of the individual phases in the composite material, and not on aggregate size. The volume of the third phase (i.e., the ITZ) in concrete remains constant because of the opposite effects of coarse aggregate size on its thickness and surface area.

The upper and lower bounds of the elastic modulus of concrete $\left(E_{\mathrm{c}+} \& E_{\mathrm{c}-}\right)$ for different coarse aggregate elastic moduli were calculated using Eq. 2. The results are plotted in Fig. 3 to determine the influence of the variation in coarse aggregate elastic modulus $\left(E_{\mathrm{ca}}\right)$ on the concrete elastic modulus $\left(E_{\mathrm{c}}\right)$. It can be observed from

Table $2 E_{\mathrm{m}}$ and $E_{\mathrm{ic}}$ values calculated for different values of hcp capillary porosity.

\begin{tabular}{|c|c|c|}
\hline$P_{\mathrm{h}}$ & $E_{\mathrm{m}}(\mathrm{GPa})$ & $E_{\text {ic }}(\mathrm{GPa})$ \\
\hline 0.05 & 40.25 & 13.46 \\
\hline 0.10 & 31.14 & 8.73 \\
\hline 0.15 & 25.70 & 6.14 \\
\hline 0.20 & 21.71 & 4.34 \\
\hline 0.25 & 18.50 & 2.98 \\
\hline 0.30 & 15.76 & 1.90 \\
\hline 0.35 & 13.29 & 1.01 \\
\hline 0.36 & 12.81 & 0.84 \\
\hline 0.37 & 12.33 & 0.68 \\
\hline 0.38 & 11.83 & 0.50 \\
\hline 0.39 & 11.32 & 0.25 \\
\hline
\end{tabular}

Fig. 3 that the variations in the upper bounds for $E_{\mathrm{c}}$ with changes in coarse aggregate elastic modulus tend to be more pronounced when compared with those in the lower bounds. However, the overall variations in concrete elastic modulus with changes in coarse aggregate elastic modulus are small enough to justify selection of an average value of $80 \mathrm{GPa}$ for the coarse aggregate elastic modulus.

After establishing the upper and lower bounds for the elastic modulus of concrete, the next step was to narrow down these bounds and develop a reasonable model of concrete elastic modulus for use towards development of the concrete strength model. This was accomplished by introducing the concrete elastic modulus values obtained from an empirical model based on comprehensive experimental results (Ramakrishnan and Arunacha-

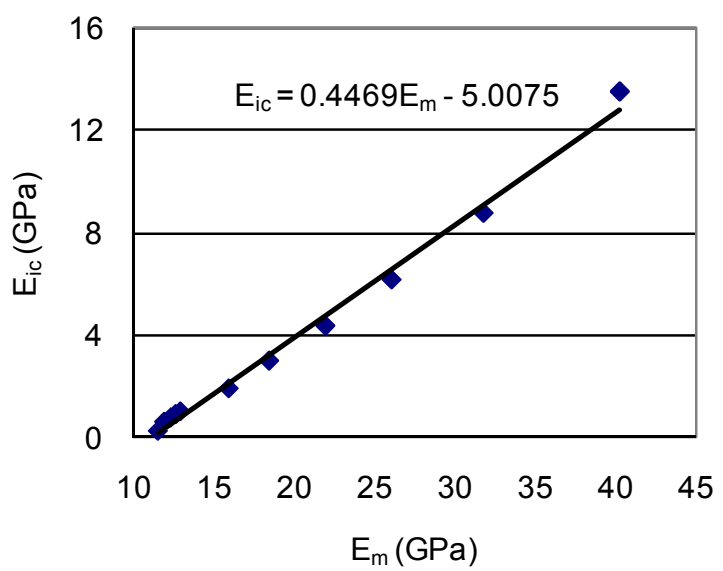

Fig. 2 Relationship between elastic moduli of cement mor$\operatorname{tar}\left(E_{\mathrm{m}}\right)$ and ITZ $\left(E_{\mathrm{ic}}\right)$ in concrete.
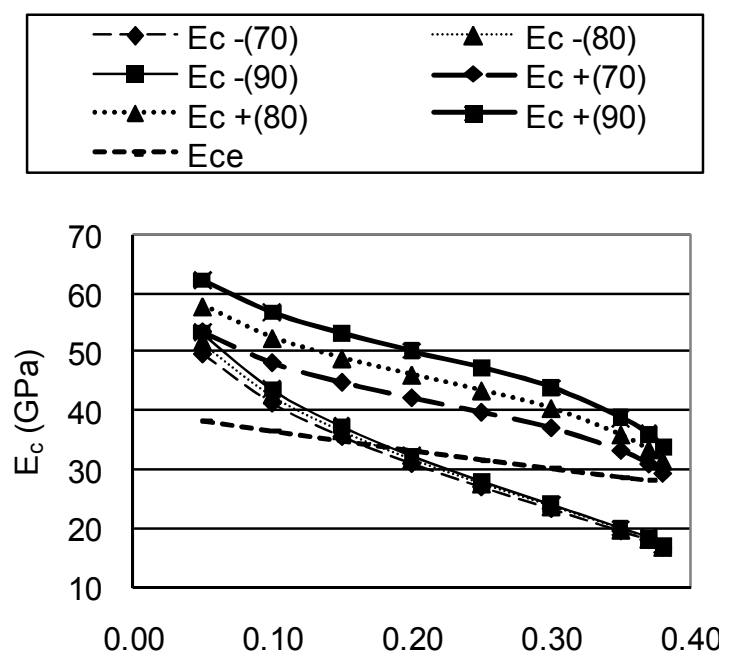

Capillary porosity

Fig. 3 Comparison of theoretical predictions of concrete elastic modulus with those of an empirical model $\left(E_{\mathrm{ce}}\right)$. 
lam 1990) into Fig. 3 (denoted $E_{\mathrm{ce}}$ ), where the experimental results (represented by the empirical model) are observed to lean towards the lower-bound values of the theoretically predicted elastic moduli.

Based on the data presented in Fig. 3, the lowerbound theoretical model was chosen to represent the elastic modulus of concrete. The modulus of elasticity of concrete was thus approximated as follows:

$$
E_{c} \approx \frac{9 K_{c-}^{\prime} G_{c-}^{\prime}}{3 K_{c-}^{\prime}+G_{c-}^{\prime}}
$$

where $E_{\mathrm{c}}$ is the modulus of elasticity of concrete (in $\mathrm{GPa})$.

With the aggregate elastic modulus $\left(E_{\mathrm{ca}}\right)$ estimated at $80 \mathrm{GPa}$, substituting the parameters in Eq. 21 with their relevant equations presented earlier yields the following expression for the concrete elastic modulus as a function of the cement mortar elastic modulus.

$$
E_{c} \approx \frac{4.02 E_{m}^{2}-45.09 E_{m}}{0.023 E_{m}^{2}+1.96 E_{m}-24.38}
$$

where $E_{\mathrm{m}}$ is the modulus of elasticity of cement mortar (in $\mathrm{GPa}$ ):

$$
E_{m} \approx \frac{5.78 E_{h}^{2}-28.35 E_{h}}{0.04 E_{h}^{2}+2.43 E_{h}-12.46}
$$

where $E_{\mathrm{h}}$ is the modulus of elasticity of the hep (GPa).

\section{Mechanistic model for fracture toughness of concrete}

The fracture toughness of concrete benefits greatly from the frictional pull-out of coarse aggregates, which accompanies pull-out of $\mathrm{CH}$ crystals adhering to the coarse aggregate surfaces. Coarse aggregates have rough surfaces that improve the bonding of cement mortar through the ITZ (Fig. 4).

The computation of the fracture toughness of concrete was based upon the energy dissipated during the pullout of coarse aggregates. This process involves phononic friction as the cement mortar dendrites bonding to the coarse aggregate surface shear off (Fig. 4). Phononic friction is the energy dissipation mechanism, at the nano level, when solids slide against each other (Meyer et al. 2002). The energy dissipation mechanism as the rough surface of aggregate pulls out from the mortar was treated as phononic friction (Persson 1998). The crack shielding effect associated with coarse aggregates also contributes to the fracture toughness by enhancing the formation of a process zone in front of a crack tip. It was assumed that each dendrite of cement mortar is subjected to a shearing force from the matching dendrite defining the coarse aggregate rough surface, acting at the centers of their contact surfaces. This produces a diagonal tensile stress within the dendrites of cement mortar, generating close to 45-degree diagonal cracks as shown in Fig. 5. When the coarse aggregate pulls out of the cement mortar, its rough surface exerts a stress on the mortar dendrites, and shears them off. The total surface area of the cement mortar subjected to this action was approximated to be about half the pulled-out surface area of the coarse aggregate.

The surface area of the coarse aggregate subjected to pull-out and debonding was computed by considering the cylindrical coarse aggregate model shown in Fig. 6. The shaded region in Fig. 6 is the mean surface area of the coarse aggregate subjected to frictional pull-out.

\section{Energy released by debonding of coarse aggregates}

The surface area of a coarse aggregate subjected to debonding and pull-out, $A_{\text {cad }}$, (in $\mathrm{m}^{2}$ ) is:

$$
A_{c a d}=2.25 \pi r_{c a}^{2}
$$

The oriented $\mathrm{CH}$ crystals create planes of weakness around the aggregate surface. To account for this effect

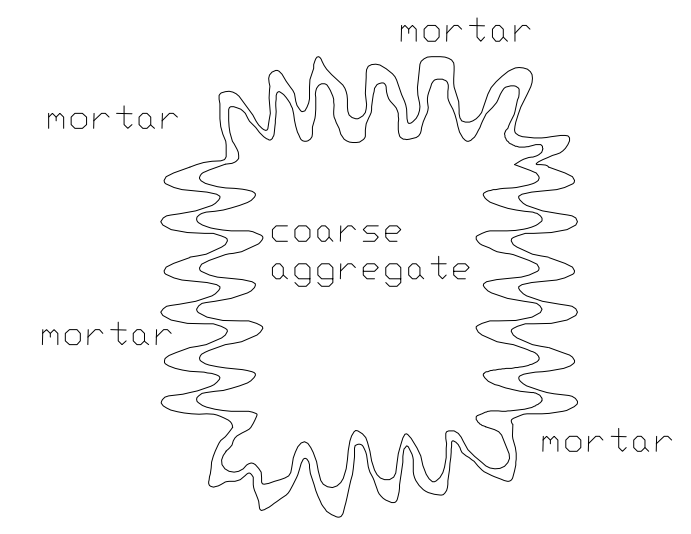

Fig. 4 Surface roughness of coarse aggregate, which benefits bonding to mortar via ITZ.

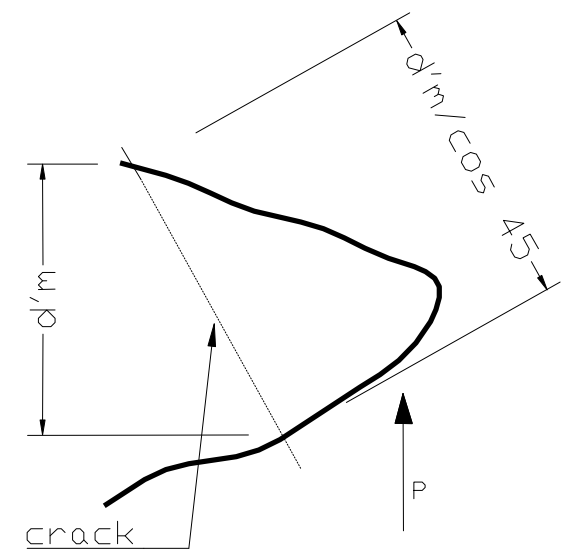

Fig 5 Crack pattern of cement mortar dendrite due to force $\mathrm{P}$ associated with coarse aggregate pull-out action. 


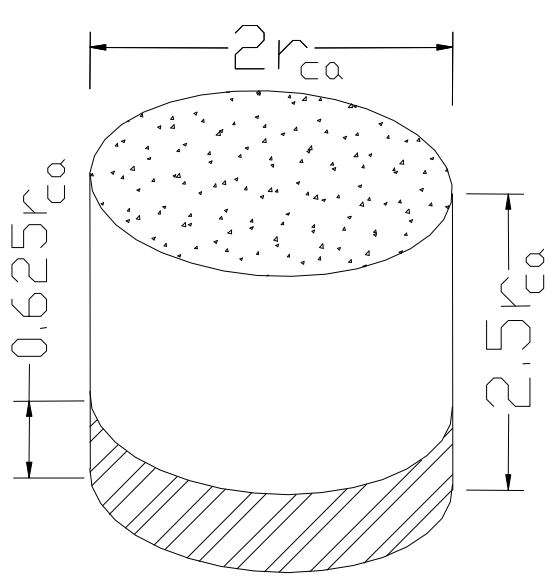

Fig. 6 Average surface area (shaded) of aggregate particle subjected to frictional pull-out.

and also the porosity of the ITZ (which is about twice that of the bulk hcp), Eq. 24 is modified as follows:

$$
\Rightarrow A_{c a d}^{\prime}=2.25 \pi r_{c a}^{2}\left(1-2 P_{h}\right)
$$

The total energy dissipated during concrete cracking is the sum total of the energy dissipated by the cracking of mortar and that consumed by the debonding/pull-out of coarse aggregates in the ITZ. The energy lost due to the debonding of C-S-H globules, which is equal to 1.56 $\mathrm{J} / \mathrm{m}^{2}$, and the fracture toughness of cement mortar, which is $91.78 \mathrm{~J} / \mathrm{m}^{2}$, are used here towards calculation of the fracture toughness of concrete (Ghebrab and Soroushian 2010). The energy consumed ( $U_{\text {cad }}$, Joules) by the debonding of coarse aggregate from the hcp (in the ITZ) is calculated using the above relationship as follows:

$$
\begin{aligned}
& U_{c a d}=1.56 A_{c a d}^{\prime} \\
& \Rightarrow U_{c a d}=3.51 \pi r_{c a}^{2}\left(1-2 P_{h}\right)
\end{aligned}
$$

The energy released per unit fractured area of the ITZ $\left(G_{\text {cad }}\right.$, in $\mathrm{J} / \mathrm{m}^{2}$ ) due to C-S-H/C-S-H debonding can be calculated as the total debonding energy of one coarse aggregate divided by the projected area of the aggregate on a plane perpendicular to the pull-out direction (see Eqs. 28 and 29).

$$
\begin{aligned}
& G_{c a d}=\frac{3.51 \pi r_{c a}^{2}}{\pi r_{c a}^{2}}\left(1-2 P_{h}\right) \\
& \Rightarrow \quad G_{c a d}=3.51\left(1-2 P_{h}\right)
\end{aligned}
$$

\section{Energy released during pull-out of coarse aggregates}

The surface area of a coarse aggregate subjected to frictional pull-out $\left(A_{\text {cap }}\right.$, in $\left.\mathrm{m}^{2}\right)$ is the shaded area of the cylinder in Fig. 6 (excluding the bottom surface):

$$
A_{c a p}^{\prime}=1.25 \pi r_{c a}^{2}\left(1-2 P_{h}\right)
$$

When the dendrites of the cement mortar shear off due to aggregate pull-out, the fractured diameter of the dendrites is about $1.414 d_{m}^{\prime}$ (due to the diagonal shear effect), as shown in Fig. 5. Due to the assumption that the dendrites of both cement mortar and coarse aggregate are interlocked (Fig. 4), the total surface area of the cement mortar subjected to shear stress $\left(A_{\text {capm }}\right.$, in $\left.\mathrm{m}^{2}\right)$ is about 1.414 times $A^{\prime}$ 'cap. Therefore,

$$
\begin{aligned}
& A_{\text {capm }}^{\prime}=1.414 \times 1.25 \pi r_{c a}^{2}\left(1-2 P_{h}\right) \\
& \Rightarrow A_{c a p m}^{\prime}=1.77 \pi r_{c a}^{2}\left(1-2 P_{h}\right)
\end{aligned}
$$

The energy released due to $\mathrm{CH}$ pull-out when $A^{\prime}$ capm fractures $\left(\mathrm{U}_{\text {chcap } 1}\right.$, in Joule) can be calculated as the product of the modified $G_{\mathrm{pm}}$ and $A_{\text {'capm, }}$, as shown in the following equation, where $G_{\mathrm{pm}}$ is the energy per unit surface area released due to $\mathrm{CH}$ pull-out in a compact cement mortar paste, which is equal to $91.78 \mathrm{~J} / \mathrm{m}^{2}$.

$$
\begin{aligned}
& U_{\text {chcap } 1}=91.78 A_{\text {capm }}^{\prime} \\
& \Rightarrow U_{\text {chcap } 1}=162.22 \pi r_{c a}^{2}\left(1-2 P_{h}\right)
\end{aligned}
$$

Let $\mathrm{U}_{\text {chcap2 }}$ (in Joule) represent the energy released due to $\mathrm{CH}$ pull-out at the bottom surface of the aggregate particle. It can be calculated as the product of the modified $G_{\mathrm{p}}$ and the base area of the coarse aggregate:

$$
U_{\text {chcap } 2}=91.78 \pi r_{c a}^{2}\left(1-2 P_{h}\right)
$$

The total energy released due to $\mathrm{CH}$ pull-out during the pull-out of the aggregate particle from the cement mortar $\left(U_{\text {chcap }}\right)$ is, therefore, the sum of $U_{\text {chcap1 }}$ and $U_{\text {ch- }}$ cap2, that is:

$$
\begin{aligned}
& U_{\text {chcap }}=U_{\text {chcap } 1}+U_{\text {chcap } 2} \\
& \Rightarrow U_{\text {chcap }}=254 \pi r_{c a}^{2}\left(1-2 P_{h}\right)
\end{aligned}
$$

The energy released per unit fractured area of the ITZ ( $G_{\text {chcap }}$, in $\mathrm{J} / \mathrm{m}^{2}$ ), due to $\mathrm{CH}$ pull-out, is the total energy released as one coarse aggregate pulls out divided by the projected area of the aggregate on a plane perpendicular to the pull-out direction:

$$
\begin{aligned}
& G_{\text {chcap }}=\frac{254 \pi r_{c a}^{2}\left(1-2 P_{h}\right)}{\pi r_{c a}^{2}} \\
& \Rightarrow G_{\text {chcap }}=254\left(1-2 P_{h}\right)
\end{aligned}
$$

The total energy release rate per unit fractured area of the ITZ in concrete $\left(G_{\text {ic }}\right.$, in $\left.\mathrm{J} / \mathrm{m}^{2}\right)$ can be calculated as the sum of $G_{\text {chcap }}$ and $G_{\text {cad }}$ :

$$
\begin{aligned}
& G_{i c}=G_{\text {chcap }}+G_{\text {cad }} \\
& \Rightarrow G_{i c}=257.5\left(1-2 P_{h}\right)
\end{aligned}
$$


The other factor that enhances the fracture toughness of concrete is the shielding of crack growth. Coarse aggregates cause a crack shielding or arresting effect by bridging between the two crack surfaces near a crack tip. This phenomenon causes multiple microcracking ahead of the crack tip within the cement mortar. For the volume fractions of coarse aggregate commonly used in concrete, formation of the process zone increases the fracture toughness of cement mortar by about $50 \%$. Therefore, the modified fracture toughness of compact mortar (due to the crack shielding effect of coarse aggregates) is approximated as $1.5 \times 91.78=137.67 \mathrm{~J} / \mathrm{m}^{2}$ (Li and Maalej 1996). Therefore, the modified fracture toughness of mortar, $G_{\mathrm{m}}\left(\right.$ in $\left.\mathrm{J} / \mathrm{m}^{2}\right)$ is:

$$
G_{m}=137.67\left(1-2 P_{h}\right)
$$

The fracture toughness of concrete $\left(G_{\mathrm{c}}\right.$, in $\left.\mathrm{J} / \mathrm{m}^{2}\right)$ can be calculated as the sum of the fracture toughness associated with the debonding/pull-out at the ITZ and that of the modified cement mortar, accounting for the respective volume fractions of coarse aggregates and mortar:

$$
G_{c}=G_{i c} V_{c a}^{\prime}+G_{m} V_{m}^{\prime}
$$

where $V_{c a}^{\prime}$ is the volume fraction of coarse aggregates (including ITZ) in concrete; and $V_{m}^{\prime}$ is the volume fraction of the cement mortar in concrete. Using the example (typical) values of $V_{c a}^{\prime}=0.455$ and $V_{m}^{\prime}=0.545$, and substituting for $G_{\text {ic }}$ and $G_{\mathrm{m}}$, in Eq. 43 yield:

$$
\begin{aligned}
& G_{c}=117.21\left(1-2 P_{h}\right)+75.05\left(1-P_{h}\right) \\
& \Rightarrow G_{c}=192.2\left(1-1.61 P_{h}\right)
\end{aligned}
$$

The resulting values of $G_{\mathrm{c}}$ are plotted in Fig. 7 versus the capillary porosity of the hcp. The basis for this relationship is the model in Eq. 45, which was developed in section 6 in Eqs. 30 to 44.

The fracture toughness from this model for reason-

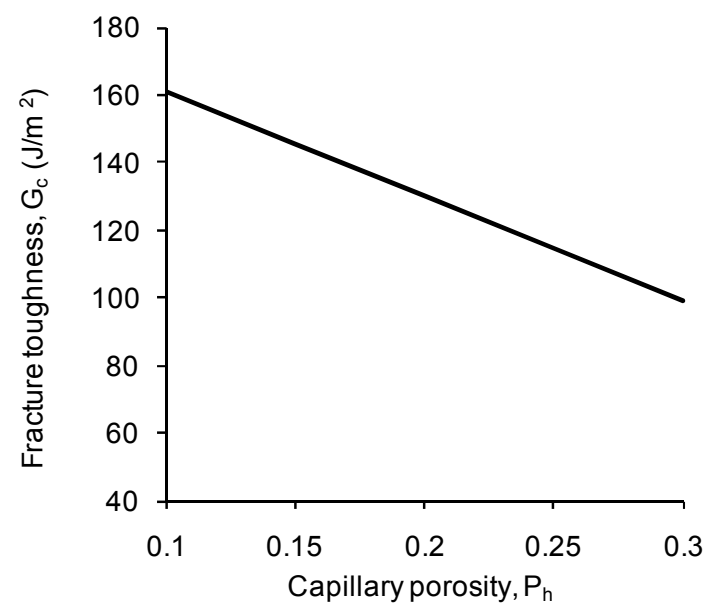

Fig. 7 Predicted fracture toughness of concrete as a function of the capillary porosity of hcp. able levels of capillary porosity ranges from 105 to 161 $\mathrm{J} / \mathrm{m}^{2}$, which is in conformance with the experimental values of the fracture toughness of concrete, which range from 100 to $200 \mathrm{~J} / \mathrm{m}^{2}$ (Giaccio and Zerbino 1998).

\section{Mechanistic model for tensile strength of concrete}

Since the tensile behavior of concrete is nearly linearly elastic at lower porosities, Griffith's equation was employed to develop the strength-porosity relationship for concrete:

$$
\sigma_{c t}=\sqrt{\frac{E_{c} G_{c}}{\pi l_{c}}}
$$

where $E_{c}=$ the elastic modulus of concrete (in $\mathrm{GPa}$ ); $G_{c}=$ fracture toughness of concrete (in $\mathrm{J} / \mathrm{m}^{2}$; and $l_{c}=$ half the critical crack length (in $\mathrm{m}$ ) at which an unstable crack propagates in concrete under tension.

Several microcracks form in concrete during its hardening due to differential shrinkage stresses prior to application of any external loads. Microcracks are expected to initiate at the ITZ and propagate into the cement mortar. The size of these cracks may vary depending on several factors, including the homogeneity of the distribution of coarse aggregates in mortar. It was assumed here that the largest existing microcrack bridges between two coarse aggregates (Bisschop and van Mier 1999, Liu et al. 2006) as shown in Fig. 8.

From Fig. 8, the initial crack length in concrete was estimated as the sum of the center-to-center distance between two coarse aggregates $\left(l_{c}^{\prime \prime}\right.$, in $\left.\mathrm{m}\right)$ and the size of coarse aggregate $\left(2 r_{\mathrm{ca}}\right)$ :

$$
l_{c}=0.5\left(l_{c}^{\prime \prime}+2 r_{c a}\right)
$$

Shrinkage cracks are more likely to occur around larger aggregates due to the fact that they block more of the bleeding water (compromising their ITZs) and also generate larger differential shrinkage stresses in their vicinity. For this reason, the maximum aggregate size in concrete was considered in computation of the critical

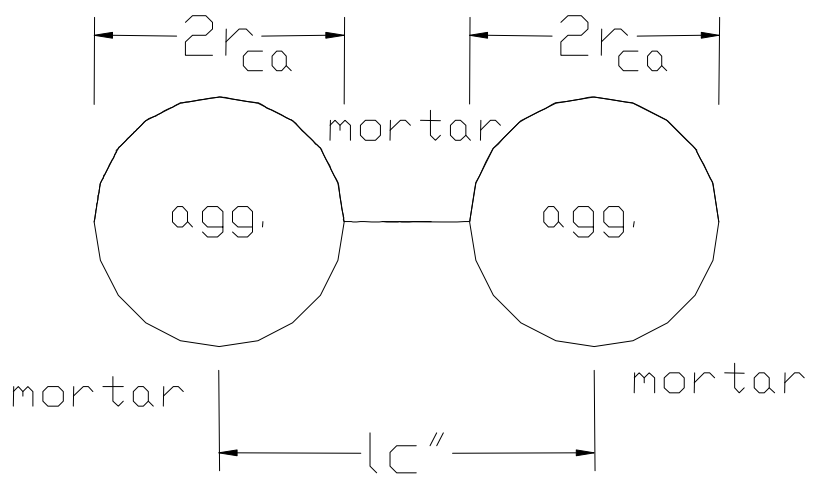

Fig. 8 Largest inherent shrinkage crack in cement mortar bridging between two coarse aggregate particles. 
crack length. If we assume a uniform distribution of coarse aggregates in cement mortar, the center-to-center spacing between two aggregates $\left(l_{c}^{\prime \prime}\right)$ can be calculated for the case with a reasonable coarse aggregates volume fraction of 0.45 as follows:

$$
\begin{aligned}
& 2.5 \pi r_{c a}^{3}=0.45 l^{\prime \prime} \\
& \Rightarrow l_{c}^{\prime \prime}=\left(\frac{2.5 \pi\left(r_{c a}^{3}\right)}{0.45}\right)^{1 / 3}=2.6 r_{c a}
\end{aligned}
$$

Substituting Eq. 49 into Eq. 47 yields $l_{c}=2.3 \mathrm{r}_{\text {ca. }}$. This means that the critical crack length is about 2.3 times the maximum aggregate size.

The tensile strength model of concrete can then be derived by substituting Eqs. 22, 45 and 49 , for $E_{\mathrm{c}}, G_{\mathrm{c}}$ and $l_{\mathrm{c}}$, respectively, in Eq. 46 . The resulting model is:

$$
\sigma_{c t}=96.4\left[\frac{\left(1-1.61 P_{h}\right)\left(E_{m}^{2}-11.2 E_{m}\right)}{d_{c a}\left(E_{m}^{2}+85.2 E_{m}-1060\right)}\right]^{1 / 2}
$$

where : $\sigma_{\mathrm{ct}}=$ the tensile strength of concrete $(\mathrm{MPa}) ; P_{\mathrm{h}}=$ the capillary porosity of hcp; $d_{c a}=$ the maximum aggregate size $\left(2 r_{\text {ca }}\right.$,in $\left.\mathrm{m}\right)$; and $E_{\mathrm{m}}=$ elastic modulus of cement mortar (in $\mathrm{GPa}$ ).

The relationship between tensile strength $\left(\sigma_{c t}\right)$ and capillary porosity $\left(P_{\mathrm{h}}\right)$ of concrete (Eq. 50$)$ is shown in Fig. 9.

The measured values of tensile strength for concrete materials with the typical fracture toughness range of the model $\left(105-161 \mathrm{~J} / \mathrm{m}^{2}\right)$ are from 4.9 to $7.6 \mathrm{MPa}$, for a maximum aggregate size of $20 \mathrm{~mm}$ (Giaccio and Zerbino 1998). The theoretical range of tensile strength derived here is from 4.5 to $9.5 \mathrm{MPa}$ for a maximum aggregate size of $20 \mathrm{~mm}$ (Fig. 9), which agrees reasonable well with the corresponding experimental range.

\section{Compressive strength model of concrete}

The failure mechanism of concrete under compression is different from that of hcp and cement mortar. Failure of hcp and mortar under compression involves the formation of straight cracks sub-parallel to the direction of the applied compressive stress. Therefore, the compressive strengths of hep or cement mortar could be estimated by comparing the lateral tensile strains caused by Poisson's effect under compression against the cracking strain. In the case of concrete, the lateral tensile stress resulting from Poisson's effect under compression produces cracks at the ITZs around coarse aggregates, and the combined effects of compressive stress and lateral strain extend these cracks in such a way that they form conical shaped hats on opposite sides of the aggregates (Fig. 10). The schematic and dimensions of Fig. 10 are based on experimental observations (Poon et al. 2000). The conical hats act as wedges to further crack the concrete as the compressive stress increases towards the peak (failure) stress. Therefore, determination of the

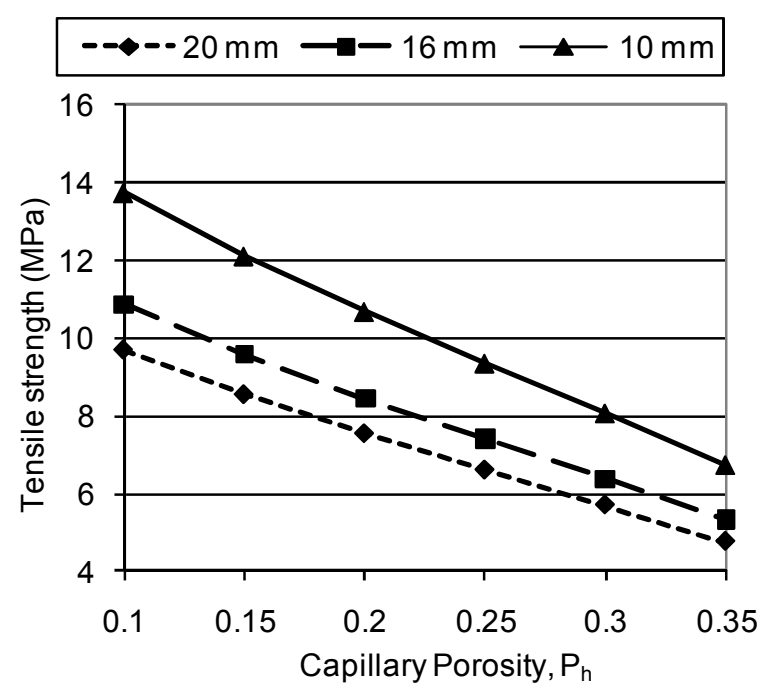

Fig. 9 Tensile strength-capillary porosity relationship for concretes with different maximum aggregates sizes.

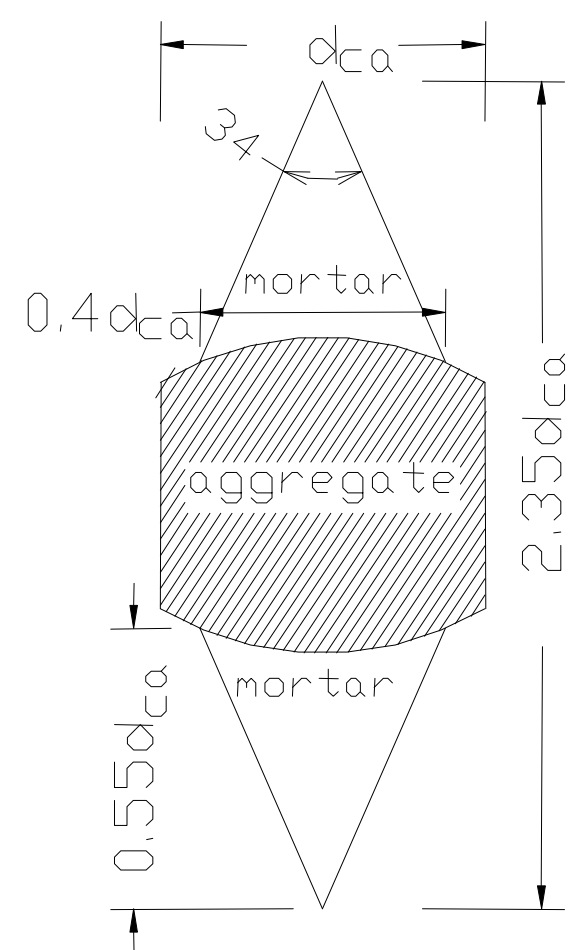

Fig. 10 Schematic of conical wedges forming above and below coarse aggregates as concrete fails under compression.

compressive strength of concrete involves computation of the frictional energy loss at conical surfaces associated with the wedging effect that leads to the failure of concrete.

The surface area $\left(S_{\mathrm{c}}\right.$, in $\left.\mathrm{m}^{2}\right)$ of one of the mortar conical wedges covering the coarse aggregate can be calculated as follows: 


$$
\begin{aligned}
& S_{c}=\pi\left(0.2 d_{c a}\right) \sqrt{\left(0.55 d_{c a}\right)^{2}+\left(0.2 d_{c a}\right)^{2}} \\
& \Rightarrow S_{c}=0.36 d_{c a}^{2}
\end{aligned}
$$

The energy dissipated as the mortar surrounding a coarse aggregate shears along the surfaces of conical wedges was considered as an addition to the fracture toughness of concrete (calculated originally under tension). Since this energy dissipation is related to the mortar phase of concrete, the additional energy ( $G_{\text {add }}$, in $\left.\mathrm{J} / \mathrm{m}^{2}\right)$ is calculated as the product of the fracture toughness of mortar and the ratio of the surface area of the wedge to the projected area of aggregate:

$$
\begin{aligned}
& G_{a d d}=\frac{S_{c}}{0.25 \pi d_{c a}^{2}}\left(G_{m}\right) \\
& \Rightarrow G_{\text {add }}=42.08\left(1-1.75 P_{h}\right)
\end{aligned}
$$

The fracture toughness of concrete under compression $\left(G_{\mathrm{cc}}\right.$, in $\left.\mathrm{J} / \mathrm{m}^{2}\right)$ was calculated by adding the contribution to fracture toughness of the conical mortar wedges $\left(G_{\text {add }}\right)$ to the fracture toughness of concrete under tension $\left(G_{\mathrm{c}}\right)$ :

$$
\begin{aligned}
& G_{c c}=G_{a d d}+G_{c} \\
& \Rightarrow G_{c c}=234\left(1-1.64 P_{h}\right)
\end{aligned}
$$

The compressive strength of concrete can then be calculated using the Griffith's equation based on the tensile implications of compression associated with Poisson's effect:

$$
\sigma_{c c}=\sqrt{\frac{E_{c} G_{c c}}{\pi l_{c} v^{2}}}
$$

where $\sigma_{c c}=$ the compressive strength of concrete $(\mathrm{MPa}) ; E_{c}=$ the elastic modulus of concrete $(\mathrm{GPa})$; $G_{c c}=$ the fracture toughness of concrete (in $\left.\mathrm{J} / \mathrm{m}^{2}\right) ; l_{c}=$ half the critical crack length in concrete $(\mathrm{m})$; and $\mathrm{v}=$ Poisson's ratio of concrete.

Expressions for the parameters of Eq. 57 have been determined in the previous section, and their substitution into Eq. 57 yields the following expression for the compressive strength of concrete:

$$
\sigma_{c c}=532\left[\frac{\left(1-1.64 P_{h}\right)\left(E_{m}^{2}-11.22 E_{m}\right)}{d_{c a}\left(E_{m}^{2}+85.22 E_{m}-1060\right)}\right]^{1 / 2}
$$

The compressive strength model of concrete presented above was evaluated by comparing its predictions versus the experimental results reported in the literature and also versus empirical models. The empirical models developed by Balshin (1949) (Eq. 59) and Ryshkevitch (1953) (Eq. 60) were used for evaluating the predictions of the above theoretical model for the compressive strength of concrete.

$$
\sigma_{c c}=68.74(1-p)^{8.15}
$$

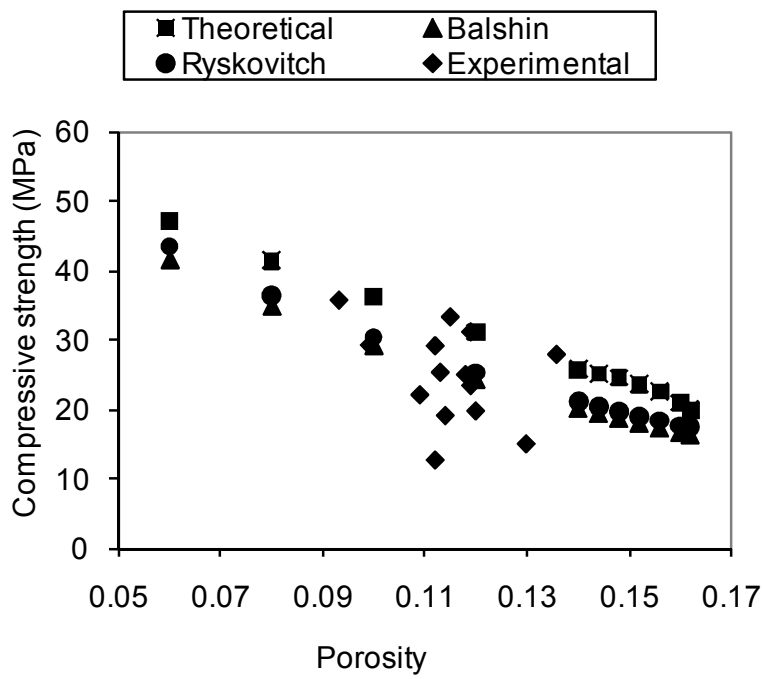

Fig. 11 Predictions of compressive strength model of concrete versus experimental results and predictions of empirical models.

$$
\sigma_{c c}=74.4 e^{-8.96 p}
$$

where $p=$ porosity.

The comparisons between theoretical predictions of compressive strength, experimental results and empirical models are presented in Fig. 11. It can be observed in Fig. 11 that the predictions of the mechanistic compressive strength model compare favorably with experimental values and predictions of the empirical models, though the theoretical predictions are slightly on the higher side.

\section{Conclusions}

The following conclusions can be drawn based on the theoretical work presented in this paper.

The elastic modulus model of concrete was developed by considering the contributions and interactions of the cement mortar, coarse aggregates, and the ITZ. The model was further verified and refined using the experimental trends reported in the literature.

The fracture toughness model of concrete highlighted the significance of the contributions made by coarse aggregates through frictional pull-out and arrest/diversion of cracks. The predictions of the fracture toughness model compared favorably with reported experimental results.

The tensile strength model of concrete was based on the corresponding elastic modulus and fracture toughness models, considering the effects of aggregates on restrained shrinkage microcracking of concrete. Predictions of the tensile strength model are in good agreement with experimental results.

The energy absorption capacity of concrete in compression benefits from the wedging action of conical cement mortar that forms in association with coarse 
aggregates in the direction of loading. The corresponding energy dissipation is due to the shear friction effects on surfaces of these conical wedges. The compressive strength model of concrete developed considering this phenomenon yields results that compare favorably with experimental results and the predictions of empirical models.

The developed models for the mechanical properties of concrete can work satisfactorily for mature concrete.

\section{References}

Balshin, M. Y., (1949). "Relation of mechanical properties of powder metals and their porosity and the ultimate properties of porous metal-ceramic materials." Dokl. Akad. Nauk. (SSSR), 67, 831-834. (in Russian)

Bisschop, J. and van Mier, J. G. M., (1999). "Quantification of shrinkage microcracking in young mortar with fluorescence light microscopy and ESEM." Heron, 44(4), 245-255.

Dhir, R. K., (2005). "Key features in view of modeling the permeability of concrete." Cement combinations for durable concrete, University of Dundee, Scotland UK. July 2005, 591-600.

Erdogan, S. T., Quiroga, P. N., Fowler, D. W., Saleh, H. A., Livingston, R. A., Garboczi, E. J., Ketcham, P. M., Hagedorn, J. G., and Satterfield, S. G., (2006). "Three-dimensional shape analysis of coarse aggregates: New techniques for and preliminary results on several different coarse aggregates and reference rocks." Cement and Concrete Research, 36, 1619-1627.

Garboczi, E. J., Bentz, D. P., Shane, J. D., Mason, T. O., Jennings, H. M., (2000). "Effect of the interfacial transition zone on the conductivity of portland cement mortars." Journal of the American Ceramic Society, 83(5), 1137-1144.

Gercek, H., (2007). "Poisson's ratio values for rocks." International Journal of Rock Mechanics and Mining Sciences, 44, 1-13.

Ghebrab, T. and Soroushian, P., (2010). "Mechanical properties of hydrated cement paste: Development of structure-property relationships." International Journal of Concrete Structures and Materials, 4(1), 37-43.

Giaccio, G. and Zerbino, R., (1998). "Failure mechanism of concrete: Combined effect of coarse aggregates and strength level." Advanced Cement
Based Materials, 31, 41-48.

Hsu, T. T. C., Slate, F. O., Sturman, G. M., and Winter, G., (1963). "Microcracking of plain concrete and the shape of the stress-strain curve." ACI Journal, 60(2), 209-224.

Li, V. C. and Maalej, M., (1996). "Toughening in cement based composites. Part I: Cement, mortar, and concrete." Cement and Concrete Composites, 18, 223-237.

Liu, J., Mukhopadhyay, A. K. and Zollinger, D. G., (2006). "Contribution of aggregates to the bonding performance of concrete." Paper submitted to the Transportation Research Board for presentation and publication at the 2006 annual meeting in Washington, D. C.

Mehta, P. K. and Monteiro, P. J. M., (1993) "Concrete: Structure, properties, and materials." $2^{\text {nd }}$ ed. PrenticeHall Inc.

Meyer, E., Overney, R. M., Dransfeld, K. and Gyalog, T., (2002). "Nanoscience: Friction and rheology on the nanometer scale." $2^{\text {nd }}$ ed. Singapore: World Scientific Publishing Co. Pte. Ltd.

Mindess, S., Young, J. F. and Darwin, D., (2003). "Concrete." 2nd ed. New Jersey: Prentice Hall.

Persson, B. N. J., (1998). "Sliding friction: Physical principles and applications." Berlin and Heidelberg: Springer (Nanoscience and Technology), 54-59.

Poon, C. S., Lam, L. and Wong, Y. L., (2000). “A study on high strength concrete prepared with large volumes of low calcium fly ash." Cement Concrete Research, 3, 447-455.

Ramakrishnan, N. and Arunachalam, V. S., (1990). "Effective elastic modulus of porous solids." Journal of Materials Science, 25, 3930-3937.

Ryshkewitch, R., (1953). "Compression strength of porous sintered alumina and zirconia." Journal of American Ceramic Society, 36(2), 65-68.

Scrivener, K. L., (1989). "Materials science of concrete I.” In: Skalny, J. P. Ed. American Ceramic Society. Westerville Ohio, 127-161.

Scrivener, K. L., Crumbie, A. K. and Laugesen, P., (2004). "The interfacial transition zone between cement paste and aggregate in concrete." Interface Science, 12, 411-421.

Yang, C., Lin, Y., Huang, R., (1996). "Elastic modulus of concrete affected by elastic moduli of mortar and artificial aggregates." Journal of Marine Sciences and Technology, 4 (1), 43-48. 